Article

\title{
Socio-Spatial Concerns in Urban Mobility Planning: Insights from Competing Policies in Quito
}

\author{
Giovanni Vecchio ${ }^{1,2, * \mathbb{D}}$, Riccardo Porreca ${ }^{2} \mathbb{D}$ and Daniela Jácome Rivera ${ }^{2}$ \\ 1 Instituto de Estudios Urbanos y Territoriales and Centro de Desarrollo Urbano Sustentable (CEDEUS), \\ Pontificia Universidad Católica de Chile, Santiago 6904411, Región Metropolitana, Chile \\ 2 Facultad de Arquitectura y Urbanismo, Universidad UTE, Calle Rumipamba s/n y Bourgeois, Quito 170508, \\ Ecuador; riccardo.porreca@ute.edu.ec (R.P.); daniela.jacome@ute.edu.ec (D.J.R.) \\ * Correspondence: giovanni.vecchio@uc.cl
}

Received: 29 January 2020; Accepted: 26 March 2020; Published: 7 April 2020

\begin{abstract}
Socio-spatial concerns are gaining increasing attention in the design of interventions for urban mobility. This is especially true in contexts traditionally characterized by structural inequality and high levels of poverty, in which transport can be a decisive contributor to development thanks to its contribution to a higher social inclusion. Amongst them, Latin America has emerged as a significant laboratory for urban and transport policy due not only to its socioeconomic conditions but also to the implementation of different mobility strategies based on the construction of traditional and innovative infrastructures such as subways and bus rapid transit (BRT) systems. These two transport systems can be complementary or alternative to each other: this depends not only on their transport capacity, their economic sustainability, and to their levels of public acceptability but also on social, political, and spatial features of the setting they serve. This paper intends to discuss the socio-spatial consequences that interventions based on different transport systems can generate, examining them in the city of Quito, Ecuador. The discussion is based on the implementation of the existing BRT network and of a subway line under construction. Reconstructing two contrasting transport policies developed in the city in the last 25 years, this paper proposes an overview of the socio-spatial concerns that influenced and were influenced by urban mobility planning in Quito. To do so, this paper reviews and compares the socio-spatial concerns related to BRT and subway corridors, considering their accessibility, the wider urban transformations they promote, their economic sustainability, and the overall public acceptability, estimating to what extent these have influenced the decision to implement a certain transport policy.
\end{abstract}

Keywords: transport policy; social evaluation; bus rapid transit; subways; Quito

\section{Introduction}

Transport systems generate several socio-spatial consequences, which urban research and policy are increasingly considering. Transport is one of the main elements that allow people to move from one place to another and thus access those opportunities that they need in order not to be socially excluded [1-4]. Traditionally, transport planning has privileged a utilitarian approach, that focused on travel demand rather than mobility needs-this attitude enhances the efficiency of transport systems but overlooks the social impacts of mobility [5-7]. However, both scholars and policymakers are developing more socially sensitive approaches to urban mobility issues. On the one hand, academic research is exploring these concerns in the following three directions [8]: theoretical approaches devoted to transport justice and mobility justice [9-11], quantitative approaches focused on accessibility [12-15], and qualitative approaches focused on individual mobility practices [1,16,17]. On the other hand, in the last few decades, various policymakers have promoted transport-based 
strategies for tackling socioeconomic inequalities, enhancing social inclusion, and fostering urban regeneration; famous examples in this sense are the Colombian cities of Bogotá and Medellin, which have inspired several cities across the world $[18,19]$. These are just two influential cases that different international agencies have started promoting as best practices for urban mobility in metropolises of developing countries [20-22].

While transport policies may share the purpose of promoting social inclusion through enhanced mobility, the infrastructural systems at the core of these strategies are different. However, the choice of implementing a certain option is rarely based on exclusively technical evaluations. Transport policies determine several socio-spatial impacts that enhance or impede the public acceptance and therefore the political feasibility of certain options. These include a wide range of features, such as the amount and distribution of the costs and benefits generated by each measure [23,24]; the conflicts generated by a new transport policy, due to its externalities or to the disruptions in it generates $[25,26]$; or the perceptions associated with certain (often infrastructural) interventions, especially in terms of "need" and "prestige," as well as of their contribution to the "legacy" of the decision maker who promotes them $[27,28]$. These are just some of the social impacts generated by transport policies, and that the main evaluative techniques often struggle to consider [29]. Despite this, all the previously mentioned elements may contribute-knowingly or not—-to forms of complementarity or competition between different transport policies, whose implementation may depend not only on technical but also on political considerations.

In this paper, we propose to examine to what extent socio-spatial concerns influence and are influenced by urban mobility policy decisions that involve alternative transport options. Considering that a policy is "the process of choice between alternative ways to solve a collective problem" [30], our aim is to observe, specifically the sequential implementation of alternative policies based on different transport infrastructures, considering their wider impacts. To do so, we base our analysis in the city of Quito (Ecuador), which implemented a bus rapid transit (BRT) system first (opened in 1995), followed by a subway line (to be opened in 2020).

Even if Quito and its BRT system did not become as famous as that of Bogotá [31], Quito appears as a suitable case study for at least two reasons. First, the city has developed urban mobility strategies to address (also) the structural poverty and inequalities of the city, as other Latin American settings did [32-34]. Second, Latin America has been a place where BRT systems and subways have competed and where the former has somehow prevailed: "among Latin American cities with more than 1 million inhabitants, 59 percent have BRT systems, 31 percent have urban rail systems, and 25 percent have both" [21]. However, transport policy in Quito has evolved in a different way in comparison to many other cities of the region, where two tendencies can be observed. The first, which follows the (mainly) successful experiences of Curitiba and Bogotá, sees the promotion of BRT systems as a suitable option to improve urban mobility with a system cheaper than a subway network. In the second, visible for example in Santiago de Chile, BRT-like systems have complemented-with ambiguous results-established subway networks. Quito instead has followed a different route: the city has been an early adopter of the BRT system but has questioned its initial choice, deciding to implement a subway too. In this sense, the experience of Quito is different to those of other Latin American settings. Moreover, Quito has somehow resolved the transport policy conflict that characterizes other cities (for example, Bogotá, where the competition between BRT and subways is ongoing since decades). Because of this, the competing transport policies of Quito have already been object of analysis, even if from a public administration perspective [35]; a focus on their impacts on the urban mobility of Quito is instead missing and is therefore the object of this work.

The analysis of the paper draws on a critical review of academic and grey literature concerning mobility issues and transport policies in Quito. While other cities in Latin America (such as Bogotá, Medellín, Curitiba, etc.) deployed urban mobility policies that explicitly intended to generate certain socio-spatial impacts, we argue that, in Quito, socio-spatial concerns had a limited impact on the mobility planning strategies of the city—some issues were explicitly considered in planning strategies; 
others were mentioned but not assessed, reducing the effectiveness of the deployed measures; and others were simply not considered, generating unintended consequences for the transport system of Quito and the city as a whole. Developing a qualitative analysis of relevant scholarly, institutional, and journalistic sources, our analysis is structured around four variables that help to show to what extent socio-spatial concerns received attention in the urban mobility planning strategies of the city.

In order to develop this analysis, the sources considered involve different materials, such as statistic and cartographic databases; planning and policy documents, developed especially by municipal and metropolitan institutions; and academic literature devoted to planning and mobility issues in Quito found in global and regional indexation services such as SCOPUS, Web of Science, Scielo, and Latindex. The analysis is based on the review of existing works rather than on empirical analyses devoted specifically for this paper, a limitation that we acknowledge throughout the paper. The paper is structured as follows. First, Section 2 discusses four possible criteria for examining socio-spatial concerns in urban mobility planning, drawing on the literature referred to the fields of urban and transport planning and policy. After introducing the setting of Quito and its mobility system, explaining the interest in Quito as a case study (Section 3), the paper analyzes the socio-spatial implications of the existing BRT system (Section 4) and of the subway line under construction (Section 5), applying the four selected criteria and mapping them when possible. Section 6 discusses to what extent these socio-spatial concerns have influenced the decision to implement a certain transport policy and future avenues to further investigate the competition between alternative measures. The discussion summarizes the lessons learned from Quito and the results that can be valuable for other settings. Finally, the conclusions call for further research on the topic, which can expand the analysis of the four discussed dimensions through devoted quantitative and qualitative analyses.

\section{Urban Mobility and Socio-Spatial Concerns: An Analytical Framework for Examining Policy Decisions}

Alternative mobility policies may intend to achieve the same aim. The decision to implement one policy rather than another does not rely simply on technical considerations but also includes a significant political dimension, which is increasingly considered in academic research focusing on urban mobility [36,37]. The competition between alternative policies can be better understood considering the contribution they provide to key features of a certain purpose. In this paper, we examine similarities and differences of BRT and subway corridors as alternative policies that in Quito intend to achieve the same aim - that is, to improve mobility in the city by reducing congestion and facilitating the access to urban opportunities [38].

To do so, and drawing on reference [19], we propose an analytical framework to compare competing transport policies (that in this case are based on the implementation of a specific infrastructure) according to their social impacts. Four elements seem to emerge from the scientific literature, constituting a framework that for each policy considers: the accessibility it provides, its impacts on the spatial organization of a territory, its economic sustainability and its public acceptability.

From a social perspective, accessibility is probably the main impact that a transport policy generates. The consolidated research on transport-related social exclusion tends to agree on the importance of accessibility to activities rather than on mobility of itself, as Lucas [39] highlights in her brief overview of the topic. According to different authors, accessibility is crucial to contrast social exclusion and to enhance one's quality of life, thanks to the access it provides to relevant opportunities and social relationships $[1,2,4,14,17,40]$. To guarantee fair mobility systems, accessibility should be considered as a social good [41] and should become the main aim of transport planning [9]. Nonetheless, a transport policy is only one of the elements that can contribute to accessibility. Considering accessibility as "the extent to which land-use and transport systems enable (groups of) individuals to reach activities or destinations by means of a (combination of) transport mode(s)" [42], the transport dimension is equally important as the organization of the spatial setting in which it operates and the features of the individuals who need to access opportunities. 
A transport policy can also affect the spatial organization of a territory. Considering the distribution of inhabitants and activities, variations in accessibility can affect the functioning of a city in planned or unintentional ways. The first is the case for transit-oriented developments (TODs), which concentrate higher densities and attractive functions in areas where existing or new transport systems grant higher levels of accessibility (see Jamme et al. [43] for a review of the concept); the stations and the stops along a certain infrastructure have a different potential for development, depending on the available transport services and on the surrounding land uses (what Bertolini [44] considers in his Node-Place model), suggesting different forms to propose new urban developments along transport corridors [45]. For example, the city of Curitiba intentionally increased urban density along the BRT corridors of the city, promoting a pioneering form of transit oriented development already in the late 1960s [46-48]. The second is the case for increased land values, which often originate forms of gentrification around transport corridors-a phenomenon that has been investigated in different settings [49-52]. The arrival of more affluent groups who replace previous inhabitants is especially problematic for socially focused transport policies, whose potential beneficiaries may be expulsed and forced to move to cheaper areas with poorer levels of accessibility. This unintended counter-effect was visible, for example, in the case of Bogotá and its socially inspired BRT system [53]. Intended and unintended impacts on the spatial organization of a territory are thus fundamental to understand the social consequences of a certain transport policy.

The economic sustainability of a transport policy is instead crucial to understand its evolution throughout all the steps of a policy cycle - from the definition of the problem to be addressed to the evaluation of the achieved results. The evaluation of costs and benefits is an established feature of traditional transport planning, a discipline strongly influenced by economic disciplines [54]. Nonetheless, economic sustainability is particularly important in the case of socially oriented transport policies and especially in developing countries. The limited availability of economic resources requires the adoption of original measures, as in the celebrated cases of Bogotá and Medellin; the former chose to implement a BRT system because it was 10 times cheaper than the construction of a subway system, while the latter implemented a system of urban cableways to connect informal impervious areas that, otherwise, would have required much more invasive (and expensive) interventions. The economic sustainability of a transport policy requires considering also how its costs and the benefits are distributed between different key actors, an element strictly related to the last point of this framework.

Finally, public acceptability is as relevant as economic sustainability for granting the successful design, implementation, and maintenance of a transport policy. A policy problem requires different actors to define it as such. In relation to a certain policy, different actors may play different roles-from active promoters of a solution to mild supporters or bold opposers; other subjects instead may be relevant even without playing an active role, as in the case of the general public. The public acceptability is crucial to understand the success or failure of a certain policy, whose outcome does not simply depend on its technical features but also on how different actors receive it. Moreover, in the case of socially oriented transport policies, public acceptability may also be relevant from the perspective of procedural justice, considering that a certain measure granting fair outcomes should be the result of a fair decisional process. In this sense, policy discourses and power dynamics are fundamental to examining the procedures leading to a certain policy decision.

In the next sections, the socio-spatial consequences of alternative transport policies will be considered, drawing on the four elements here described. The proposed framework is intentionally limited. On the one hand, each of the proposed items is worthy a devoted analysis, considering, for example, how the examined transport systems enhance accessibility or the forms of governance deployed in the city-it would be relevant to develop work devoted to the accessibility granted by the public transport systems in order to investigate how public transport helps to tackle social exclusion by granting access to urban opportunities for disadvantaged population groups. On the other hand, the socio-spatial consequences of alternative transport policies may include other features, such as the experiences they imply for different users or the immaterial impacts they generate. Nonetheless, 
the proposed framework allows us to grasp essential elements, enough to consider the socio-spatial consequences of transport policies and to what extent these affect planning decisions.

\section{The Setting of Quito: Reasons for Choosing the Case Study}

The Metropolitan District of Quito (DMQ) is the capital of Ecuador and is situated in an area of approximately $4218 \mathrm{~km}^{2}$, with a population of 2.4 million inhabitants [55]. The city, located at an average of 2800 meters above the level of the sea, is organized into eight Operative Zonal Administrations (OZAs), composed by 65 parishes, 33 of which are considered rural and 32 urban [56]. The rural parishes include $91.2 \%$ of the entire DMQ area, while the urban parishes include $8.8 \%$. Geomorphologically, the urban part of Quito is located in the highest plain surface of Los Andes Valley and consists of valleys and mountains. Its volcanic origin reveals a discontinuous surface with a series of ravines that in many cases (especially in the city "hypercenter") have become impervious surfaces and result in flooding areas-a situation that often affects the normal public and private traffic flows [57]. Moreover, the presence of mountains creates a natural border that conditions the urban expansion to the west. Instead, the low slope to the east allowed a transversal expansion to the valleys of Nayón, Cumbayá, Tumbaco, and Los Chillos. After the fast urban expansion during the period from 1950 to 1980, when Quito grew by $500 \%$ and its density decreased quickly [58,59], the city started to expand to the east valleys, producing high-income areas with a very low density (eight inhabitants per hectare).

Today, the urban area covers approximately $45 \mathrm{~km}$ along a north-south axis, while the expansion in the east valleys covers up to $16 \mathrm{~km}$ from the center. In general, the urban area is characterized by a low density, having approximately 46 inhabitants/hectare. The city of Quito revolves around two main centralities. The first is the historic center, the best preserved in Latin America; today it maintains a commercial vocation, while it is experiencing a certain diminution in the number of inhabitants $(-18 \%$ between 2001 and 2010; [55]). The second is the "hypercenter" close to the northern border of the historic center. It acts as the central business district of Quito, being the economic and service center of the city, as the number of daily attracted trips demonstrates (approximately half a million trips per day). In the rest of the city, low-density residential areas prevail, constituting residential areas that are functionally dependent on the two centers. To address their need of mobility towards the central areas of the city, the public transport system is key. First, a BRT system was introduced in 1995; today, it is composed of three lines (Ecovía, Metro Bus, and Trolebús) that intersect in nodal stations located in Carcelen, Quitumbe, and La Marin, which also act as interchange nodes for the local bus lines serving the peripheries. In addition, a subway line along the same north-south corridor is currently under construction and expected to be opened in 2020. Table 1 recalls their basic features, while Figures 1 and 2 show their location in the city.

Table 1. Summary of the basic features of bus rapid transit (BRT) and the subway in Quito.

\begin{tabular}{ccc}
\hline & BRT & Subway \\
\hline Length & $71 \mathrm{~km}$ & $22 \mathrm{~km}$ \\
Stations & 126 & 15 \\
Daily passengers & 745,000 & 360,000 (expected) \\
\hline
\end{tabular}




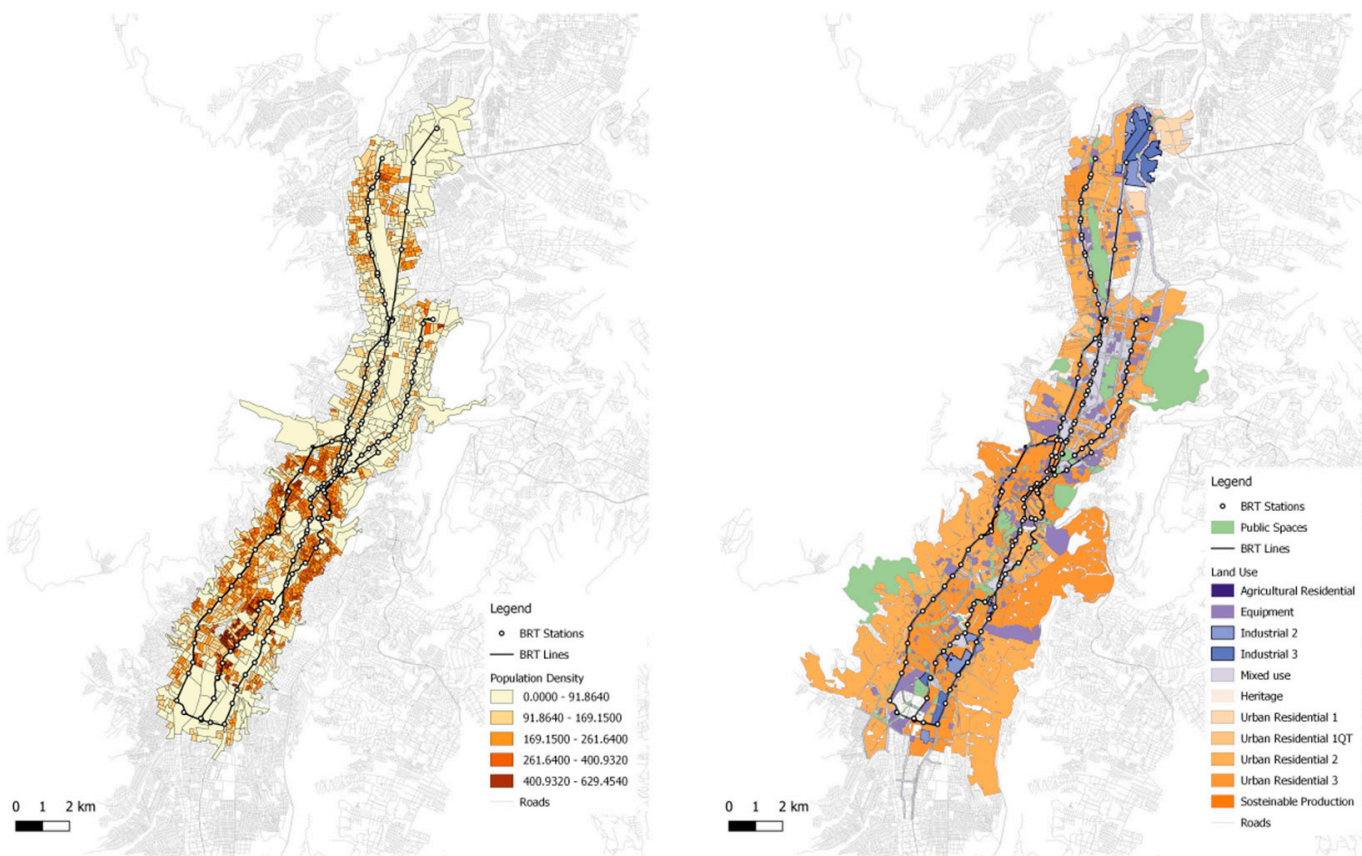

Figure 1. BRT network in Quito: (left) BRT and population density; (right) BRT and land uses.

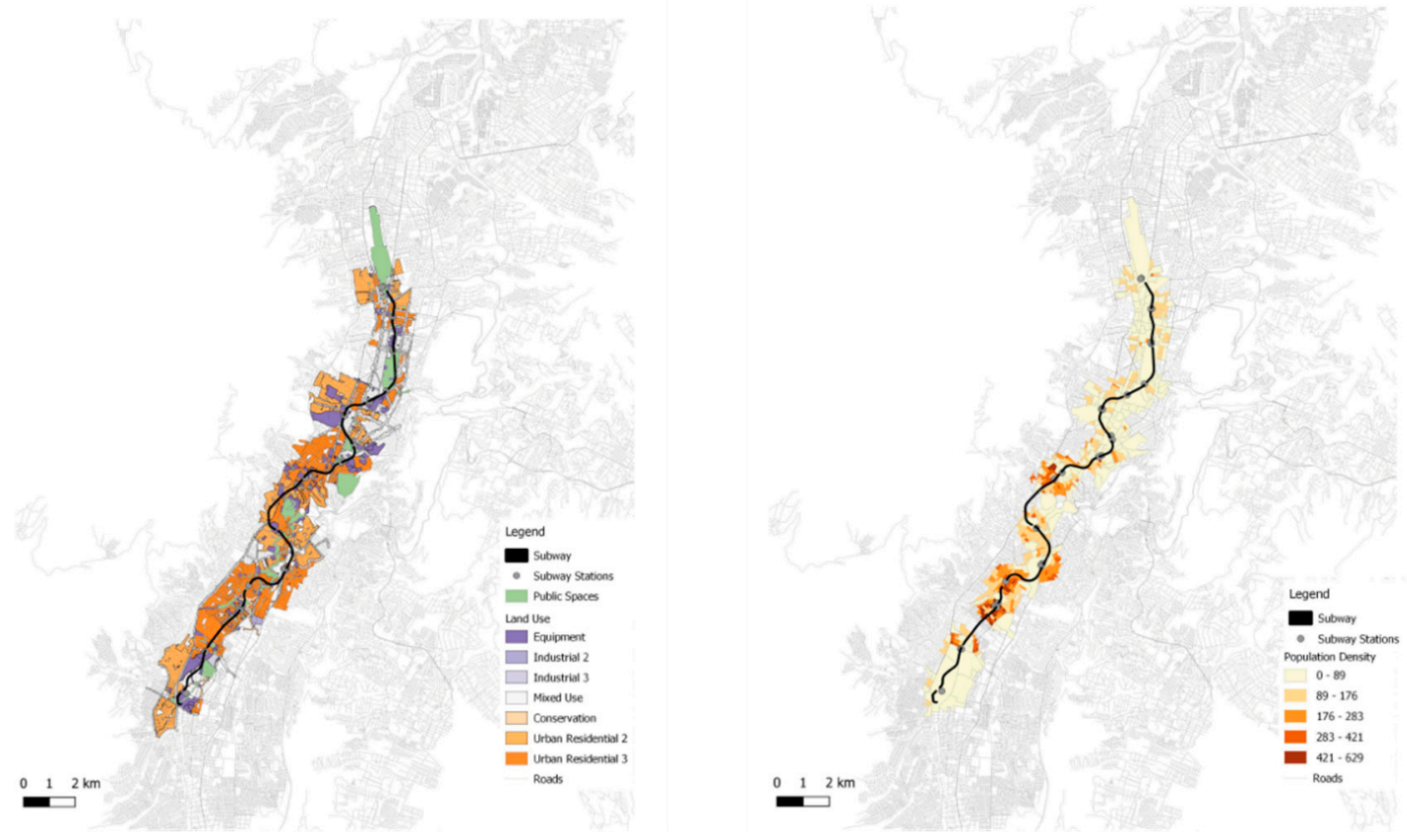

Figure 2. Subway line in Quito: (left) subway and population density; (right) subway and land uses.

Quito offers a suitable case study of how socio-spatial concerns affect mobility planning, allowing a comparison between the implementation of two different transport systems. Different settings in the Global South - and especially in Latin America, which has been a precursor in this sense-have developed new public transport systems as a tool to enhance social inclusion and, more in general, improve the conditions of mobility for their inhabitants. In most cases, the improvement of urban mobility has relied on new public transport systems (given that a significant share of the inhabitants in Global South cities have low income and therefore have no access to private motorized vehicles; growing motorization rates in some of these countries are a more recent phenomenon). However, this improvement faced two alternative possibilities: (1) develop heavy infrastructures, such as subways, 
which are efficient but also expensive, or (2) develop light infrastructures, such as BRT, which have performances similar to those of subways but have much smaller construction costs. The dilemma we deal with has been clearly faced by academic research as well as by international organizations interested in urban development issues (such as UN Habitat, the World Bank, etc.), who have often promoted BRT systems as a fast, relatively cheap solution to enhance urban mobility in Global South cities. This explains our interest in comparing two alternative systems such as BRT and subway, without considering other travel modes for which no specific policies were developed, and that were never considered alternative to each other.

Quito provides valuable elements for considering a transport policy dilemma that involves many other settings, in Latin America, the Global South and the Global North (considering for example those cities that, following renowned best practices such as Bogotá's, are evaluating the possible implementation of BRT systems). First, Quito was one of the first cities to implement a BRT network. Following the example of Curitiba and discarding the possibility of building a subway, the capital of Ecuador decided to realize a BRT system that was initially opened in 1995. This was five years before Bogotá's TransMilenio started its operation. The experience of Quito was relevant, although it did not receive the same international recognition as Bogotá since it resulted difficult to involve Quito's political actors in international promotional initiatives (as Montero [31] discusses). Considering this aspect, as well as comparing the amount of work published on Bogotá's TransMilenio with the scarcity of works devoted to Quito, we can deduce that Quito's BRT would be as interesting as Bogotá for a devoted study focusing on transport. It did not receive much attention mainly due to its lack of international visibility. In addition to this, as we mention Quito is one of the few cities where the BRT/subway dilemma has been faced sequentially, first privileging the bus-based system and then implementing the rail-based system; many other cities instead are still dealing with debates on the opportunity to build a subway in addition to the existing BRT network. Quito thus allows us to compare the different effects of two transport systems often considered as alternative to each other; moreover, it allows a comparison that is not theoretical or focused on the simple technical features of the two systems but rather is able to consider their specific social consequences in place, examining them in a well-defined spatial setting.

Apart from the specific interest in relation to transport issues, Quito is a significant case study since it reflects various trends that are relevant also for other medium-sized cities in the Global South: it is the capital of a developing country, whose economy is strictly associated to the US dollar. Quito and Ecuador are experiencing a strong economic and demographic growth, reflected also in fast urban expansion; at the same time, the uncontrolled expansion of Quito determines a strong socio-spatial segregation. Despite these issues, Quito has hosted the UN Habitat III conference in 2016, which demonstrates the international relevance of the city.

\section{BRT and Its Socio-Spatial Features}

The BRT system of Quito is composed of three corridors, with a network of 71 kilometers and 126 stations [60]. These follow the north-south alignment of the city, serving especially the central areas in which the better-off population is concentrated. The population with direct access to the stations of the system, considering a walkable distance of 600 meters (based on references [61-64]), amounts to the $31 \%$ of Quito's inhabitants. This percentage may increase if we consider also feeder services that allow to reach the BRT routes. These play an important role, considering that the paratransit services existing before the implementation of the BRT were converted into feeder services without structural changes. The current Metropolitan Plan of Development and Territorial Planning (PMDOT_Plan Metropolitano de Desarrollo y Ordenamiento Territorial) gives an important space to these services today and in the future, for example estimating that the BRT services and the feeder lines will cover the $23 \%$ of the travel demand of Quito in 2025 [65]. At the same time, the feeder services maintained some features typical of paratransit systems that affect the regularity of the service-for example, the services are unscheduled and keep competing with each other for carrying passengers [66]. 
The structure of the BRT system and the development of the city of Quito determine nonetheless a public transport system that is unequally available to different socioeconomic groups, an aspect ignored by current planning documents. The system in fact tends to serve central consolidated areas, where medium- and high-income inhabitants reside, while worst-off groups tend to live in newer and more peripheral areas [67]. This gap between public transport provision and disadvantaged socioeconomic groups can be found in other Latin American cities that have developed transport-based strategies to tackle social exclusion, such as Bogotá [68], Cali [69], and Lima [70]. As a result, some areas of the city are subject to forms of public transport deprivation [71] — these are visible when the supply of public transport (calculated in relation to stops, vehicle capacity and service frequency) is not sufficient to meet the local transport need (calculated considering the number of local inhabitants). The disadvantaged groups of Quito are affected by both their income and location, since they belong to the lowest income quintile (which includes $18 \%$ of the population) and live in the newer peripheral areas where scarcer is the availability of public transport services [71]. The BRT system therefore does not seem to effectively reduce the existing socio-spatial inequalities of Quito, although a more precise evaluation of the accessibility granted by the public transport would be required to better assess the social impacts of implementing a BRT system.

The BRT itself intervened on the spatial organization of Quito, affecting real estate development around the system corridors. The issue has been object of devoted studies, which have also compared Quito with other cities that have implemented BRT systems - such as for example Bogotá [48,72]. Instead, planning documents do not show a concern for the consequences that implementing the BRT has for the spatial organization of the city. In general, in the examined areas a remarkable growth was observed, especially as for the construction of flats and offices in tall buildings. Growth in land use values was detected only in some cases: for example, the Corredor Norte showed an increase that was not visible around the Ecovía and Trolebús corredors (which actually showed similar or even lower values in comparison with zones not served by the BRT). Instead, the cost of offices in the zone of the Ecovía grew considerably, thanks to its proximity to the "hypercenter"'of the city where many jobs (and therefore job-related trips) are concentrated. Moreover, an overall decrease of available single-family houses was visible in the zones both close and far from the BRT corridors, reflecting a tendency to urban densification and a higher availability of flats; this tendency is even stronger around Ecovía, where no change in the available single-family houses was observed in the analysis. In addition, the areas that showed higher growth rates are not those with higher levels of transit orientation (that is, built environment features promoting the use of public transport, for example via pedestrian accessibility). As a general conclusion, it emerges that, in Quito and elsewhere, "BRT has the potential to influence land development, but conditions are very context dependent" [72].

Thanks to their economic sustainability, BRT systems prove to be a convenient solution for urban settings with significant urban mobility issues and scarce resources to tackle them. The main element that contributes in this sense are the construction costs of the BRT infrastructure, which for the three BRT trunks ranges between \$1.4-5.5 million USD per kilometer-a sum considerably lower than that required for a subway system, also in the case of Quito [73]. The possibility to adapt existing road infrastructures for the BRT services, avoiding the construction of underground or aerial systems, is one of the main elements of success for BRT systems, which grant a high capacity system delivered with faster and cheaper construction works: in this way, today the three trunks carry 745,000 passengers per day, approximately twice the number of expected users for the subway line under construction [60]. Another important element of economic sustainability is the fare that passengers pay for using the BRT. Currently, the regular fare for each trip is \$0.25 USD, reduced to \$0.12 USD for children and elderlies. Even if the lack of integration between services is problematic, since it requires to pay every time a new service is used, the fare is quite low. Moreover, it remained unchanged for many years, as a result of a political decision-as in other settings, fares are intentionally much lower than the costs of the service so that also low-income groups can access the BRT system [74]. 
The acceptability of the BRT system has instead proven to be a critical feature in the case of Quito, even if planning documents do not directly mention it. The design, implementation and operation of this transport policy in fact has been characterized by conflict and the use of power, as some studies have deeply discussed $[38,75]$. The implementation of the BRT is the result of a top-down process, in which municipal elected authorities decided to sequentially realize non-integrated corridors [74]. During the implementation, the public perception of the project was reflected in at least three different attitudes that emerge from the reviewed literature. The first one refers to the promoting coalition, led by the Mayor and composed by decision makers, technicians, national academics and international consultants who put forward the idea of a BRT system. Their main argument was the need to address pressing public concerns providing a better public transport system, not only to improve the existing low-quality services but also to fight road congestion and the consequent air pollution [38]. The second one refers to the opposition of existing transport operators, who resisted the introduction of the BRT since it would have deprived them of their income source; despite negotiations with the municipality and an agreement for managing the new lines, different internal limitations of the operators resulted in their exclusion from the operations of the new systems, being thus replaced by the Municipality itself [38]. The third refers instead to the general public, who desired an improvement of the public transport and therefore supported the construction of the BRT, although no participation in the BRT planning process was granted to them [38]. It appears therefore that a widespread agreement on the public issue to be faced (in Quito, road congestion and air pollution) is crucial to grant consensus for a specific transport policy and to effectively contrast even organized forms of opposition to it.

\section{The Subway in Quito: Spatial Decisions and Their Consequences}

The subway line currently under construction is expected to play a primary role for Quito's mobility, possibly generating relevant but also ambiguous urban impacts. Reflecting the structure of the city, the line would follow a north-south axis, with 15 station along the $22 \mathrm{~km}$ of the first trunk. The line itself would be directly accessible to only a small portion of the local population: considering a buffer of 600 meters (see above) around the future stations, approximately 235,190 inhabitants- $11 \%$ of the total population of Quito-would have walkable access to the future infrastructure. The subway is expected to play a key role at a wider metropolitan scale. The PMDOT in fact states that the subway should become the backbone of Quito's mobility, fostering the intermodality between different forms of public and private transport, reducing travel times and enhancing connectivity [65]; in a city where public transport already covers the $73 \%$ of motorized trips, the subway is expected to reinforce this sustainable modal share and should accommodate $15 \%$ of the mobility demand in 2025 [65]. The statement made in the PMDOT suggests that the subway and the BRT corridors should be complementary, running close to each other and having catchment areas that would often overlap (Figure 3). The subway should contribute to a more general restructuring of Quito's public transport, currently based on the BRT, but existing plans do not provide hints on the restructuration of the existing system. Because of this, it is not clear to what extent the BRT and the subway will be complementary to or in competition with each other. 

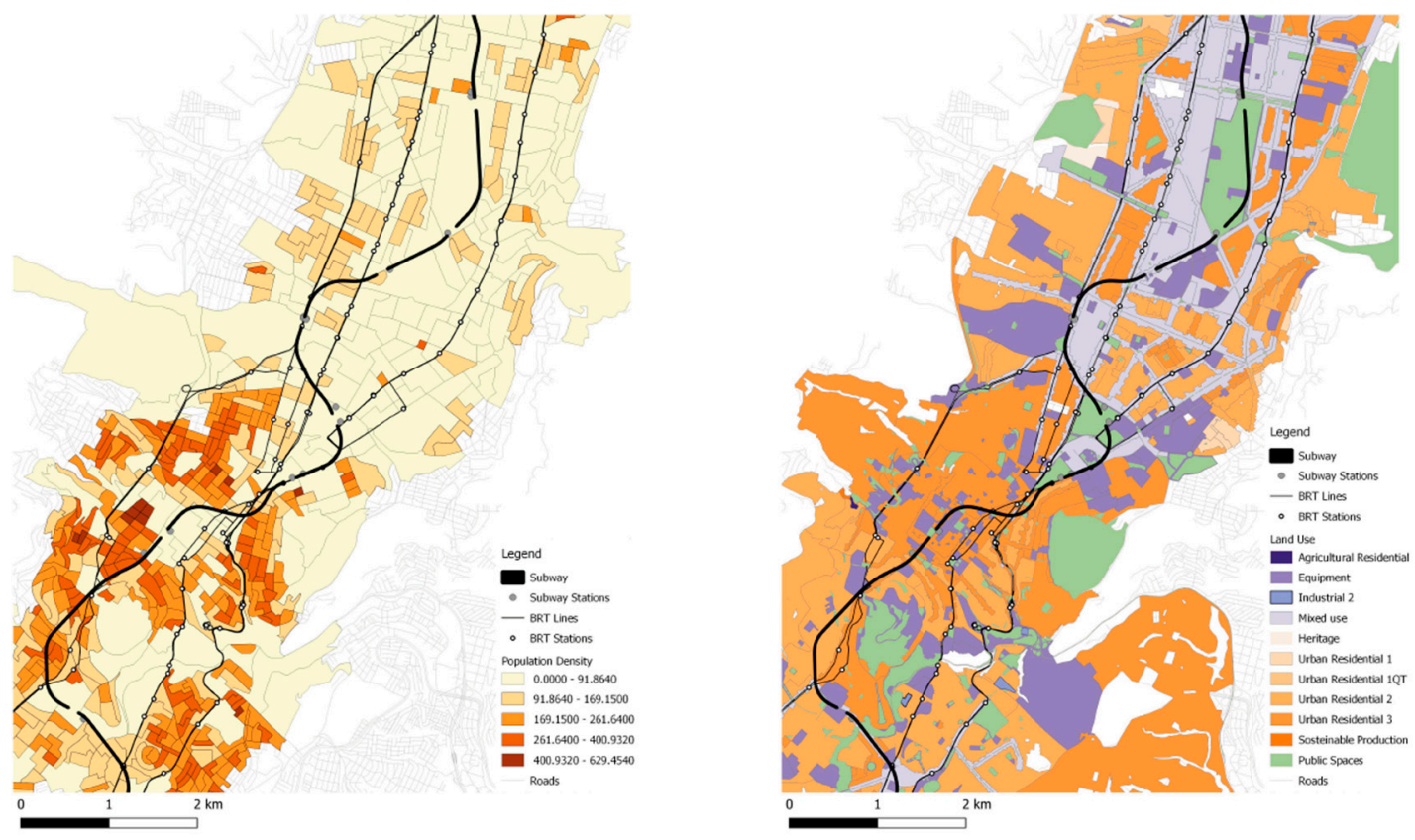

Figure 3. Proximity and overlaps of BRT corridors and subway in Quito: zoom on the historic center and the hypercenter.

The social concern related to the subway appears to be serious if we consider what areas and populations would take advantage of it. Supposedly, Ecuador is departing from mainstream neo-liberal policies, and Quito's Metro is contributing in this sense, since it "materially and symbolically accomplishes this agenda by aiming to distribute democratic rights to urban citizens to move within the city" [76]. Nonetheless, the subway—at least with its first line-is conceived as an infrastructure for the middle- and high-income areas of Quito, located in the center and the north of Quito. Existing and new services, such as four new cableways, are expected to complement the service provided by the subway and expand the public transport alternatives available to different groups of the population; nonetheless, these exclude the most segregated groups who reside in the metropolitan peripheries and who need to rely on different forms of informal transport [76,77]. The apparent focus of the subway on certain areas and groups of Quito thus requires us to carefully consider the distribution of the future benefits generated by the subway, requiring devoted and more detailed analyses of accessibility to the subway and the enhanced access it would provide to urban opportunities.

The spatial organization of Quito will probably undergo considerable changes after the opening of the first subway line. As seen in Figure 2, currently, four stations (El Calzado, Solanda, El Recreo, and San Francisco) are located in high-density residential areas of the city, while another (La Magdalena) will serve a medium-density residential zone. On the other hand, seven stations will serve high-density tertiary areas of the hypercenter (El Ejido, Universidad Central, La Pradera, La Carolina, Iñaquito, Jipijapa, and El Labrador). However, the subway will play a crucial role in the future, considering that planning documents declare it as the backbone of a strategy that intends to strengthen different centralities at the metropolitan scale. A Special Plan of Intervention for Quito Metropolitan Corridor (Plan Especial de Intervención para el Corredor Metropolitano de Quito) is being developed to foster new urban developments along the subway line, including new public spaces and public services. However, the increased accessibility and attractiveness of the areas served by the subway may generate benefits available only to the affluent groups of the population. A renewed interest in areas previously ignored, such as those of the city center, may increase the land value, could result in the expulsion of worst-off inhabitants (as happened around some stations of the Bogotá's BRT system [62]). Also, this higher attractiveness may also foster processes of gentrification, like those already ongoing in Quito's historic city center [78]. 
Even the wider economic costs and benefits related to the subway show a nuanced situation that planning documents do not explicitly mention but that are central in the public debate on the project. A first element of attention is the cost related to the construction and the maintenance of Quito's Metro. Despite having required some additional loans to continue the construction works and for putting to test the infrastructure $[79,80]$, up to now the infrastructure has proved to be cheaper than other similar projects: the cost of $\$ 2010$ million USD for the whole infrastructure implies an average cost of US\$ 87 million per kilometer, while the average cost for such projects is \$97 million USD per kilometer [81]; nonetheless, the construction is characterized by severe negative externalities, such as the destruction of heritage and archaeological remnants in the city center [82]. Also, the expected benefits are somehow partial. The infrastructure is expected to carry 360,000 daily trips, contributing to a 15-minute reduction in travel times as well as to a reduction in polluting emissions [79]. Nonetheless, negative effects are forecast, too. A visible element is the economic cost associated to the use of the new subway: an estimation for the worst-off families calculates a remarkable increase in the monthly expenses for mobility, which would amount to the $27.7 \%$ of the total expenses of a low-income family whose monthly expenses for transport amounts to the $18.5 \%$ of its income [83]. These elements show that the economic costs associated with the new subway are not necessarily sustainable, especially if specific groups or issues are considered (although this would deserve further devoted investigation).

The ambiguous results of the subway probably explain why the public acceptability of the subway has been and still is an element of uncertainty, which has pushed the institutions responsible for the infrastructure to prioritize measures for consensus building. A detailed study developed in 2012, before the construction works started, investigated how different actors perceived the future transport system [83]. Involving a very wide range of subjects (from political actors to police forces, from neighbors to parking valets), the study highlighted the high uncertainty that permeated the project: in an initial stage, most influential actors had no clear opinions (as in the case of politicians and entrepreneurs) or opposed the project of the subway, passively or actively (as in the case of neighbors or associations and NGOs dealing with mobility). However, a further focus with some of these actors highlighted a mainly positive attitude, although with two caveats: first, the need to grant less uncertainty and provide more details about the subway project, also to show to the general public its advantages in comparison to alternative projects; second, the intention to avoid that the subway became a political issue and the object of debate and conflict between different parties [83].

In 2019 (when the subway was supposed to be operating), the President of Ecuador, Lenín Moreno somehow confirmed that the subway kept being a politically transversal project: as he declared in a speech, "The city is a joint construction of its people and its history. The subway of Quito is the best symbol of it: it was planes by the mayor Augusto Barrera, the mayor Mauricio Rodas built it and you Jorge [Yunda, mayor for the 2019-2023 term; n/a] will launch it. ( . . . ) It is a joint work of everyone, with everyone and for everyone" [84]. Nonetheless, the ongoing attempts of creating a "subway culture"-for example, opening the stations under construction to the citizens or collaborating with the city of Medellin to imitate its programme of "citizen culture" seems to show that the inhabitants of Quito have not appropriated the subway system yet [85].

\section{Discussion}

The analysis of the literature demonstrates that, despite a certain interest in Quito's urban issues, there is a lack of scientific research on the city. This suggests that both review and empirical studies may shed light on this territory and the form that global issues assume in it. In this sense, this paper aims to enhance a still lacking academic debate on the developing urban transport policies in Quito and their wider urban consequences.

\subsection{Urban Mobility Planning and Socio-Spatial Concerns: A Synthesis for Quito}

The socio-spatial implications that the existing BRT and the future subway of Quito have shown demonstrate how these concerns affect the planning decisions involving different transport policies, 
although only partially. The two projects in fact have quite different implications in relation to the four analytical categories used in this paper-accessibility, spatial organization, economic sustainability, and public acceptability. The development of both system spatial frameworks leaves out large areas and conditions them in the four categories of analysis, producing disadvantaged urban neighborhoods. Even more interestingly, decision makers and the general public seem to explicitly take into account only some of these aspects. Table 2 provides a summary of the socio-spatial consequences of the two policies, as recounted in the previous sections.

Table 2. Summary of the socio-spatial concerns related to BRT and the subway in Quito.

\begin{tabular}{|c|c|c|c|}
\hline & & BRT & Subway \\
\hline \multirow{2}{*}{ Accessibility } & $\begin{array}{l}\text { People within the catchment } \\
\text { area }(600 \mathrm{~m})\end{array}$ & $\begin{array}{c}712,960 \text { ( } 32 \% \text { of Quito's total } \\
\text { population) }\end{array}$ & $\begin{array}{c}235,190 \text { ( } 11 \% \text { of Quito's total } \\
\text { population) }\end{array}$ \\
\hline & Areas served & $\begin{array}{l}\text { Central consolidated areas, } \\
\text { with medium- and } \\
\text { high-income inhabitants }\end{array}$ & $\begin{array}{c}\text { Central consolidated areas, with } \\
\text { medium- and high-income } \\
\text { inhabitants }\end{array}$ \\
\hline $\begin{array}{l}\text { Spatial organization } \\
\text { of the city }\end{array}$ & Effects on urban growth & $\begin{array}{l}\text { Unplanned growth, } \\
\text { concentrated only in some } \\
\text { areas }\end{array}$ & $\begin{array}{l}\text { Planned through the Special } \\
\text { Plan of Intervention for Quito } \\
\text { Metropolitan Corridor, drafted } \\
\text { for the areas surrounding the } \\
\text { subway }\end{array}$ \\
\hline \multirow[t]{2}{*}{$\begin{array}{c}\text { Economic } \\
\text { sustainability }\end{array}$} & Fares & $\begin{array}{l}\text { \$0.25 USD per trip; no } \\
\text { integrated fares }\end{array}$ & $\begin{array}{l}\text { To be defined; no integrated } \\
\text { fares currently defined }\end{array}$ \\
\hline & Construction costs & $\$ 1.4-55$ M USD $/ \mathrm{km}$ & $\$ 87 \mathrm{M}$ USD $/ \mathrm{km}$ \\
\hline \multirow[b]{2}{*}{ Public acceptability } & Promotion of the project & $\begin{array}{l}\text { Municipality (top-down } \\
\text { approach) }\end{array}$ & $\begin{array}{l}\text { Municipality (top-down } \\
\text { approach) }\end{array}$ \\
\hline & Public reception & $\begin{array}{l}\text { Overall public approval; } \\
\text { opposition by traditional } \\
\text { public transport operators }\end{array}$ & $\begin{array}{l}\text { Overall public neutrality; } \\
\text { uncertainty on the impacts of } \\
\text { the subway }\end{array}$ \\
\hline
\end{tabular}

From a transport perspective, both the BRT system and the subway line are expected to be the backbone of Quito's urban mobility. The two systems are conceived as a crucial element of the city transport system not just for the number of passengers they are able to carry, but rather for their overall impact on the public transport of Quito. In the case of the BRT, this role is played by replacing the former paratransit services and rearranging them into a system of feeder lines for publicly managed high capacity routes. In the case of the subway, the single line (expected to be part of a more complex underground network in the future) is intended as the central element of a newly restructured public transport system, allowing faster trips and reducing therefore overall travel times in the city. More importantly, both academic research and official planning documents recognize that the main aim of the two policies is to reduce congestion. Therefore, the BRT and the subway are expected to make Quito's urban transport system more efficient, even if no details are provided on how to restructure existing services to avoid redundancies with the new subway line. No explicit concerns refer to the urban accessibility that both policies provide. Similarly, in both policies, the most peripheral and worst-off areas are not served - they have to rely on precarious public transport services or even on varied informal alternatives. Therefore, the social consequences of urban mobility-in terms of what urban opportunities are available to what socioeconomic groups thank to the implemented measure-seem to be absent from the evaluations that supported both policies. Moreover, the incoming 2020 census may provide the base for a future research work aimed to create a primary database of new information to better characterize what social and spatial consequences transport policies may generate.

Considering instead the spatial organization of the city, the BRT system and the subway line act in almost opposite ways. As ex-post evaluations highlight, the BRT generated scattered impacts, contributing to high real estate growth rates that were visible in areas not served by the new transport infrastructures. At the same time, the enhanced accessibility provided by the corridors further strengthened the city hypercenter, which already was the main pole for job opportunities in Quito. 
The BRT thus generated spatial effects that were mainly unintended and regressive. The case of the subway is different, at least in terms of future planning intentions. The underground railway has become the structuring element of a metropolitan masterplan, intending to realize a highly accessible north-south corridor where to concentrate new services and real estate developments. Considering this and the enhanced accessibility of the areas around the new infrastructure, it is expected that the metro will have a strong impact on the spatial organization of the city, even if this should be the result of an ex-ante strategy (at least in the intentions of the public institutions promoting the plan). In this case, devoted research would be crucial to define indicators able to assess the direct and indirect spatial impacts of existing policies and future interventions.

The economic sustainability of the two policies is probably the main driver behind their implementation. Both the BRT and the subway in fact share the same policy aim-to tackle Quito's urban congestion and air pollution by improving the city public transport system. However, the BRT is initially discussed as the policy that can achieve this aim at a lower price. Quito, as in the later but more famous case of Bogotá, chose to implement a system based on fast buses because it allowed high capacity at a much lower cost than a heavy transport infrastructure (according to [86], in low income countries a new BRT system has an average cost of \$11.5 million USD per kilometer, while heavy rail systems such as subways have an average cost of $\$ 87.4$ million USD per kilometer). The decision of implementing a subway system came much later, in a moment when the BRT was no longer able to accommodate Quito's mobility demand and a complementary system was required. However, the economic dimension is fundamental even for the subway, so that the possibility to reduce the construction costs was widely celebrated by institutional and economic actors. More ambiguous is instead the economic sustainability of the two policies for the transport users, especially in the case of low-income groups. While the public transport fare is kept low due to a political decision, the structure of the public transport system requires using various services-and therefore paying higher fares-especially for those people living in peripheral and poorer areas. The new subway is expected to similarly generate an increase in the household transport expenses, impacting especially low-income families. According to the uncertain economic situation of Ecuador, whose government is still implied in an agreement process with the International Monetary Fund, future observation of the financial sustainability of the subway operation will be crucial to assess the actual affordability of the intervention.

Finally, the public acceptability of both policies is a main concern for the design, implementation, and operation of both policies, although in different ways. The BRT was promoted by a top-down approach, in a coalition of public decision makers, technicians, and academics that actively promoted a specific transport policy to address shared collective issues such as congestion and air pollution. That overall agreement allowed decision makers to easily face the structured opposition of bus operators, who first negotiated with the government and then exited the policy arena mainly due to internal weaknesses. Different is instead the case of the subway that in Quito seems to generate mixed reactions in the local actors despite being usually regarded as a "prestige" infrastructure. This interpretation seems to be supported by the events that the society responsible for developing the subway arranged to make the future infrastructure known.

\subsection{Urban Mobility Planning and Socio-Spatial Concerns: Relevant Issues for Other Settings}

Socio-spatial concerns can have a significant influence on urban mobility planning and policy, raising several issues that go beyond the mere transportation field and can affect each stage of a policy cycle. While the analysis of this paper is focused on Quito and therefore deals with its specific spatial, social, and political features, the approach proposed for the analysis can raise issues that can be relevant also for other settings: the relevance of accessibility analyses, the impacts that go beyond the mere urban mobility field, and the role of the social context of planning.

The concept of accessibility, although not much considered in Quito's planning strategies, allows to shift the focus of transport plans and policies from one of the objects they deal with-the 
infrastructure- to the function it carries out-granting access to urban opportunities. As is increasingly highlighted by the scholars concerned with the social impacts of transport, accessibility is the concept that best reflects such social impact. In relation to urban mobility plans and policies, accessibility can have a twofold relevance. First, when assessed, it allows us to observe how a certain infrastructure or policy enhances or impedes the access of certain groups to certain urban opportunities-for example, in Quito, it may highlight if the new subway line fosters access to job opportunities for the peripheral low-income communities on the city. Second, it can be an interpretative key to observe to what extent policymakers take into account socio-spatial concerns when deciding on a certain urban mobility measure (even considering the presence or absence of accessibility evaluations in a transport planning process). In most cases in fact evaluations tend to draw on models that consider how a transport system responds to the demand of users but overlook the needs of those people who may have limited possibilities to move. A focus on accessibility may help to shed light on these groups-for example, showing the extent to which a new infrastructure can enhance the quantity and quality of opportunities that a peripheral community can reach.

The decisions of urban mobility planning can also affect the spatial organization of a territory, which becomes a crucial criterion for assessing the wider socio-spatial impacts of transport. The enhanced accessibility of the areas served by a new transport infrastructure can determine for example an increased demand by functions that can afford higher rents, determining thus a rise in land use values. For example, in Quito, the BRT resulted in a growth of land use values in some cases; in Bogotá, this same growth (as a result of the implementation of a BRT system) determined the expulsion of low-income residents from areas that the new transport infrastructure served [53,87]. Since urban mobility decisions affect the spatial (re)organization of a territory, to properly deal with socio-spatial concerns, it is necessary to consider how the context of accessibility changes after a certain intervention is deployed: not only to observe to what extent transport allows certain groups to reach certain activities, but also to examine how a new transport system can fosters the relocation of such groups and such activities. Therefore, it is crucial to consider a territory in a dynamic way, going beyond the simple focus on ex-ante and ex-post evaluations of urban (mobility) interventions.

Finally, socio-spatial concerns can differently influence urban mobility planning decisions depending also on the examined social context. In Quito, the predominance of municipal political actors characterized the planning processes leading to the implementation of both the BRT and the subway. However, the former received strong support from scholars, consultants, and the general public, who saw the infrastructure as a key intervention against air pollution and road congestion; the latter instead had a less warm reception. To understand if and how urban mobility planning considers socio-spatial concerns, it is thus relevant to examine the relevant actors in the policy arena of a certain setting. This can help to identify how they influence the local policy agenda and to what extent they can influence the choice between alternative interventions. Planning and policy decisions in fact do not simply rely on technical or objective evaluations in relation to transport-despite being a file traditionally dominated by technical approaches. Such consideration can have a twofold relevance. On the one hand, it helps us to consider the context variables that in a setting can determine the failure of a (transport) intervention that elsewhere was successful, as investigated by scholars working on policy mobility [88-90]. On the other hand, it allows us to consider to what extent non-technical considerations influence a policy process, referring for example to public concerns, different actors' objectives, or even to the "thirst for prestige transport infrastructures" [27].

\subsection{Limitations of the Study}

The dimensions examined in the paper can be investigated further to overcome some of the limitations that affect the present study. Referring to Quito, a relevant issue is the need to develop first-hand analyses of the dimensions discussed in Section 2. For example, it would be relevant to collect and examine data in order to assess the accessibility provided by both the BRT and the subway, to quantify the changes in land values to assess the forms of spatial reorganization these interventions 
foster, or even to observe in detail the economic figures of the two mobility policies here examined. Similarly, it could be significant to systematically interview key actors in the urban mobility field to consider the different power dynamics associated with the policy processes for urban mobility interventions in the city. Each of these dimensions would probably require devoted work using the available data and trying to produce new data. In this way, the discussion of each dimension may rely not only on the analysis of existing sources but also on the examination of new data, which could be relevant also for other works. These analyses would allow us to replicate more sophisticated studies devoted to the socio-spatial impacts of urban mobility interventions that, in Latin America, have been developed only in some of the main metropolises of the region [15]. Moreover, an analysis based on primary data would also facilitate comparative analyses, considering how different settings dealt with the same socio-spatial concerns-for example, in terms of enhanced accessibility, progressive or regressive forms of spatial restructuring, or economic feasibility of the proposed interventions.

\section{Conclusions}

Considering this overview, different transport policies raise manifold socio-spatial concerns that decision makers only partially consider and that could be further investigated with both quantitative and qualitative research. In the case of Quito, some of these seem to be perceived as a primary role: this is the case for efficiency, economic sustainability and public acceptability; other dimensions instead tend to be considered as a secondary concern, as in the case of the city spatial organization, or are simply overlooked, as in the case of accessibility. The competition between alternative policies seems to be mainly determined by the economic dimension - that is, the cost required for implementing a specific measure. Another concern, such as the efficiency of the chosen policy, is instead carefully considered in relation to each of the measures taken into account. In Quito, the competition between different transport policies thus appears to depend on the available resources to fund them, while policies alternative to each other may become complementary when the evolution of the city and its mobility changes or worsens the issue to be tackled.

In conclusion, the mentioned socio-spatial concerns appear to be relevant to understand the decisions of policymakers, but the analysis provided in the paper requires these to be complemented with other approaches, such as those based on urban economy or engineering. The reconstruction of the impact that different transport policies have on dimensions such as accessibility, spatial organization, economic sustainability, and public acceptability needs to consider how different actors perceive these dimensions. Moreover, recognizing the governance dynamics that characterize each policy and observing to what extent the four mentioned dimensions influence the interactions between different actors can be significant for these studies. The analytical framework proposed in this paper can thus be the first step toward a more structured understanding of how different social impacts determine the development of competing transport policies.

Author Contributions: Conceptualization, G.V., R.P. and D.J.R.; methodology, G.V.; investigation, G.V., R.P., and D.J.R.; resources, G.V., R.P., and D.J.R.; writing—original draft preparation, G.V.; writing-review and editing, G.V., R.P., and D.J.R.; supervision, R.P. All authors have read and agreed to the published version of the manuscript.

Funding: G.V. acknowledges the support by the Centro de Desarrollo Urbano Sustentable, CEDEUS (Conicyt/Fondap 15110020).

Conflicts of Interest: The authors declare no conflict of interest.

\section{References}

1. Cass, N.; Shove, E.; Urry, J. Social exclusion, mobility and access. Sociol. Rev. 2005, 53, 539-555. [CrossRef]

2. Kenyon, S.; Lyons, G.; Rafferty, J. Transport and social exclusion: Investigating the possibility of promoting inclusion through virtual mobility. J. Transp. Geogr. 2002, 10, 207-219. [CrossRef]

3. Lucas, K. Transport and social exclusion: Where are we now? Transp. Policy 2012, 20, 105-113. [CrossRef]

4. Preston, J.; Rajé, F. Accessibility, mobility and transport-related social exclusion. J. Transp. Geogr. 2007, 15, 151-160. [CrossRef] 
5. Litman, T. Measuring Transport System Efficiency; Victoria Transport Policy Institute: Victoria, Canada, 2013.

6. Martens, K. Basing Transport Planning on Principles of Social Justice. Berkeley Plan J. 2006, 19, 1-17. [CrossRef]

7. Van Wee, B. Land use and transport. In The Transport System and Transport Policy; van Wee, B., Annema, J.A., Banister, D., Eds.; Edward Elgar: Cheltenham, UK, 2013.

8. Pucci, P.; Vecchio, G. Enabling Mobilities. In Planning Tools for People and Their Mobilities; Springer: Cham, Switzerland, 2019.

9. Martens, K. Transport Justice: Designing Fair Transportation Systems; Routledge: New York, NY, USA, 2017.

10. Pereira, R.H.M.; Schwanen, T.; Banister, D. Distributive justice and equity in transportation. Transp. Rev. 2017, 37, 170-191. [CrossRef]

11. Sheller, M. Mobility Justice. In The Politics of Movement in an Age of Extremes; Verso: London, UK, 2018.

12. Brussel, M.; Zuidgeest, M.; Pfeffer, K.; van Maarseveen, M. Access or Accessibility? A Critique of the Urban Transport SDG Indicator. ISPRS Int. J. Geo. Inf. 2019, 8, 67. [CrossRef]

13. Lucas, K.; van Wee, B.; Maat, K. A method to evaluate equitable accessibility: combining ethical theories and accessibility-based approaches. Transportation 2016, 43, 473-490. [CrossRef]

14. Stanley, J.; Vella-Brodrick, D. The usefulness of social exclusion to inform social policy in transport. Transp. Policy 2009, 16, 90-96. [CrossRef]

15. Vecchio, G.; Tiznado-Aitken, I.; Hurtubia, R. Transport and equity in Latin America: a critical review of socially oriented accessibility assessments. Transp. Rev. 2020, 40, 354-381. [CrossRef]

16. Kaufmann, V.; Bergmann, M.M.; Joye, D. Motility: Mobility as Capital. Int. J. Urban Reg. Res. 2004, 28, 745-756. [CrossRef]

17. Larsen, J.; Axhausen, K.W.; Urry, J. Geographies of social networks: meetings, travel and communications. Mobilities 2006, 1, 261-283. [CrossRef]

18. Bocarejo, J.P.; Portilla, I.J.; Velásquez, J.M.; Cruz, M.N.; Peña, A.; Oviedo, D.R. An innovative transit system and its impact on low income users: the case of the Metrocable in Medellín. J. Transp. Geogr. 2014, 39, 49-61. [CrossRef]

19. Vecchio, G. Democracy on the move? Bogotá's urban transport strategies and the access to the city. City Territ. Archit. 2017, 4, 1-15. [CrossRef]

20. CAF. Crecimiento Urbano y Acceso a Oportunidades: Un Desafío Para América Latina; Corporación Andina de Fomento: Bogotá, Colombia, 2017.

21. Fay, M.; Andres, L.A.; Fox, C.J.E.; Narloch, U.G.; Straub, S.; Slawson, M.A. Rethinking Infrastructure in Latin America and the Caribbean: Spending Better To Achieve More; The World Bank: Washington, DC, USA, 2017.

22. United Nations Human Settlements Programme. Planning and Design for Sustainable Urban Mobility; Routledge: Abingdon, UK, 2013.

23. Di Ciommo, F.; Shiftan, Y. Transport equity analysis. Transp. Rev. 2017, 37, 139-151. [CrossRef]

24. Gössling, S. Urban transport justice. J. Transp. Geogr. 2016, 54, 1-9. [CrossRef]

25. Marsden, G.; Docherty, I. Insights on disruptions as opportunities for transport policy change. Transp. Res. Part Policy Pract. 2013, 51, 46-55. [CrossRef]

26. Pucci, P. Large Infrastructures and Conflicts: Searching for "Boundary Objects"-Reflections from an Italian Experience. In Planning and Conflict: Critical Perspectives on Contentious Urban Developments; Routledge: London, UK, 2015.

27. Rodríguez-Pose, A.; Crescenzi, R.; Di Cataldo, M. Institutions and the Thirst for "Prestige" Transport Infrastructure. In Knowledge and Institutions; Glückler, J., Suddaby, R., Lenz, R., Eds.; Springer: Cham, Switzerland, 2018; pp. 227-246.

28. Steele, W.; Legacy, C. Critical Urban Infrastructure. Urban Policy Res. 2017, 35, 1-6. [CrossRef]

29. Mottee, L.K.; Arts, J.; Vanclay, F.; Howitt, R.; Miller, F. Limitations of Technical Approaches to Transport Planning Practice in Two Cases: Social Issues as a Critical Component of Urban Projects. Plan. Theory Pract. 2020, 21, 39-57. [CrossRef]

30. Dente, B. Understanding Policy Decisions; Springer: Cham, Switzerland, 2014.

31. Montero, S. Leveraging Bogotá: Sustainable development, global philanthropy and the rise of urban solutionism. Urban Stud. 2019. [CrossRef]

32. Ardila-Gómez, A. Transit Planning in Curitiba and Bogotá. Roles in Interaction, Risk, and Change. Ph.D. Thesis, Massachusetts Institute of Technology, Cambridge, MA, USA, 2004. 
33. Dávila, J.D. Urban Mobility and Poverty: Lessons from Medellin and Soacha, Colombia; DPU, UCL and Universidad Nacional de Colombia: Bogotá, Colombia, 2013.

34. Scholl, L.; Bouillon, C.P.; Oviedo, D.; Corsetto, L.; Jansson, M. Urban Transport and Poverty: Mobility and Accessibility Effects of IDB-Supported BRT Systems in Cali and Lima; IDB: Washington, DC, USA, 2016.

35. Khan, M.S. Metro de Quito: Better or Bitter? Analysis of "Getting Around Quito" Podium 2016, $29,95-105$. [CrossRef]

36. Legacy, C.; Curtis, C.; Scheurer, J. Planning transport infrastructure: examining the politics of transport planning in Melbourne, Sydney and Perth. Urban Policy Res. 2017, 35, 44-60. [CrossRef]

37. Marsden, G.; Reardon, L. Questions of governance: Rethinking the study of transportation policy. Transp. Res. Part Policy Pract. 2017, 101, 238-251. [CrossRef]

38. Guzman, J. Understanding the Role of Power during the Implementation of BRT Systems. Ph.D. Thesis, University of Leeds, Leeds, UK, 2017.

39. Lucas, K. A new evolution for transport-related social exclusion research? J. Transp. Geogr. 2019, 81, 102529. [CrossRef]

40. Lucas, K.; Mattioli, G.; Verlinghieri, E.; Guzman, A. Transport Poverty and Its Adverse Social Consequences. Proc. Inst. Civ. Eng. Transp. 2016, 169, 353-365. [CrossRef]

41. van Wee, B.; Geurs, K. Discussing equity and social exclusion in accessibility evaluations. Eur. J. Transp. Infrastruct. Res. 2011, 11, 350-367.

42. Geurs, K.T.; Wee, B.V. Accessibility evaluation of land-use and transport strategies: review and research directions. J. Transp. Geogr. 2004, 12, 127-140. [CrossRef]

43. Jamme, H.-T.; Rodriguez, J.; Bahl, D.; Banerjee, T. A Twenty-Five-Year Biography of the TOD Concept: From Design to Policy, Planning, and Implementation. J. Plan. Educ. Res. 2019, 39, 409-428. [CrossRef]

44. Bertolini, L. Spatial Development Patterns and Public Transport: The Application of an Analytical Model in the Netherlands. Plan. Pract. Res. 1999, 14, 199-210. [CrossRef]

45. Bertolini, L. Planning the Mobile Metropolis; Macmillan: London, UK, 2017.

46. Duarte, F.; Rojas, F. Intermodal Connectivity to BRT: A Comparative Analysis of Bogotá and Curitiba. J. Public Transp. 2012, 15, 1. [CrossRef]

47. Duarte, F.; Ultramari, C. Making Public Transport and Housing Match: Accomplishments and Failures of Curitba's BRT. J. Urban Plan. Dev. 2012, 138, 183-194. [CrossRef]

48. Rodriguez, D.A.; Vergel-Tovar, E. Sistemas de Transporte Público Masivo Tipo BRT (Bus Rapid Transit) y Desarrollo Urbano en América Latina; Lincoln Institute of Land Policy: Cambridge, MA, USA, 2014.

49. Kahn, M.E. Gentrification Trends in New Transit-Oriented Communities: Evidence from 14 Cities That Expanded and Built Rail Transit Systems. Real Estate Econ. 2007, 35, 155-182. [CrossRef]

50. Chava, J.; Newman, P.; Tiwari, R. Gentrification of station areas and its impact on transit ridership. Case Stud. Transp. Policy 2018, 6, 1-10. [CrossRef]

51. Rérat, P.; Lees, L. Spatial capital, gentrification and mobility: evidence from Swiss core cities. Trans. Inst. Br. Geogr. 2011, 36, 126-142. [CrossRef]

52. Revington, N. Gentrification, Transit, and Land Use: Moving Beyond Neoclassical Theory. Geogr. Compass 2015, 9, 152-163. [CrossRef]

53. Heres, D.R.; Darby, J.; Salon, D. Do public transport investments promote urban economic development? Evidence from bus rapid transit in Bogotá, Colombia. Transportation 2009, 41, 57-74. [CrossRef]

54. Schwanen, T. Towards decolonised knowledge about transport. Palgrave Commun. 2018, 4, 1-6. [CrossRef]

55. INEC. Censo de Población y Vivienda 2010. Available online: https://www.ecuadorencifras.gob.ec/censo-depoblacion-y-vivienda/ (accessed on 27 January 2020).

56. Distrito Metropolitano de, Q. Atlas de Amenazas Naturales y Exposición de Infraestructura Del Distrito Metropolitano de Quito; Municipio del Distrito Metropolitano de Quito: Quito, Ecuador, 2015.

57. Cardenas, A. Fuerte Lluvia Inunda Calles y Provoca caos en vías de Quito. El Universo, 15 May 2017.

58. Distrito Metropolitano de Quito. Plan Metropolitano de Ordenamiento Territorial 2012-2022; Distrito Metropolitano de Quito: Quito, Ecuador, 2012.

59. Carrión, F.; Erazo Espinosa, J. La forma urbana de Quito: una historia de centros y periferias. Bull. Inst. Fr. Détudes Andin. 2012, 41, 503-522. [CrossRef]

60. Global Brt Data. Quito, Global Brt Data, 2019. Available online: https://brtdata.org/location/latin_america/ ecuador/quito/ (accessed on 7 January 2020). 
61. McCormick, R. Does Access to Green Space Impact the Mental Well-being of Children: A Systematic Review. J. Pediatr. Nurs. Nurs. Care Child. Fam. 2017, 37, 3-7. [CrossRef]

62. Rodríguez, D.A.; Targa, F. Value of accessibility to Bogotá' s bus rapid transit system. Transp. Rev. 2004, 24, 587-610. [CrossRef]

63. Daniels, R.; Mulley, C. Explaining walking distance to public transport: The dominance of public transport supply. J. Transp. Land Use 2013, 6, 5-20. [CrossRef]

64. Gutiérrez, J.; García-Palomares, J.C. Distance-Measure Impacts on the Calculation of Transport Service Areas Using GIS. Environ. Plan. B Plan. Des. 2008, 35, 480-503. [CrossRef]

65. Distrito Metropolitano de Quito. Plan Metropolitano de Desarrollo y Ordenamiento Territorial. Volumen II-Propuesta: Componente Estratégico; Distrito Metropolitano de Quito: Quito, Ecuador, 2015.

66. Ferro, P.S.; Muñoz, J.C.; Behrens, R. Trunk and feeder services regulation: Lessons from South American case studies. Case Stud. Transp. Policy 2015, 3, 264-270. [CrossRef]

67. Carrera Yepez, V.A. Addressing spatial segregation of the low-income population through comprehensive social housing projects in Quito, Ecuador. Public Sphere J. Public Policy 2017, 5, 45-74.

68. Vecchio, G. Accessibility: Enablement by Access to Valued Opportunities. In Enabling Mobilities. Planning Tools for People and Their Mobilities; Springer: Cham, Switzerland, 2019; pp. 11-26.

69. Jaramillo, C.; Lizárraga, C.; Grindlay, A.L. Spatial disparity in transport social needs and public transport provision in Santiago de Cali (Colombia). J. Transp. Geogr. 2012, 24, 340-357. [CrossRef]

70. Oviedo, D.; Scholl, L.; Innao, M.; Pedraza, L. Do Bus Rapid Transit Systems Improve Accessibility to Job Opportunities for the Poor? The Case of Lima, Peru. Sustainability 2019, 11, 2795. [CrossRef]

71. Guzman Jaramillo, A.; Philips, I.; Lucas, K. Social impact assessment: The case of bus rapid transit in the City of Quito, Ecuador. In Measuring Transport Equity; Lucas, K., Martens, K., Di Ciommo, F., Dupont-Kieffer, A., Eds.; Elsevier: Amsterdam, The Netherlands, 2019; pp. 217-229.

72. Rodriguez, D.A.; Vergel-Tovar, E.; Camargo, W.F. Land development impacts of BRT in a sample of stops in Quito and Bogotá. Transp. Policy 2016, 51, 4-14. [CrossRef]

73. Buitrón, R. Comparativo Sistemas de Transporte Masivos Quito Brt-Metro; Metro para Quito: Quito, Ecuador, 2012.

74. Hidalgo, D.; Graftieaux, P. Bus Rapid Transit Systems in Latin America and Asia: Results and Difficulties in 11 Cities. Transp. Res. Rec. 2008, 2072, 77-88. [CrossRef]

75. Chauvin, J.P. Conflicto y gobierno local: el caso del transporte urbano en Quito; Abya-Yala - FLACSO Ecuador: Quito, Ecuador, 2007.

76. Gamble, J.; Dávalos, C. Moving with masculine care in the city. City 2019, 23, 189-204. [CrossRef]

77. Guerra, V.; Skuzinski, T.S.; Shealy, T. The Extent of Informal Car Share (ICS) in Quito, Ecuador. In International Conference on Sustainable Infrastructure 2017; Asce: New York, NY, USA, 2017; pp. 432-441.

78. Osava, M. Subway Will Modernise—and Further Gentrify-Historic Centre of Quito. Inter Press Service, 30 November 2016. Available online: http://www.ipsnews.net/2016/11/subway-will-modernise-and-furthergentrify-historical-centre-of-quito/ (accessed on 6 January 2020).

79. Ucci-Unión de Ciudades Capitales Latinoamericanas. El BID Aprueba un Préstamos de 250 millones de dólares Para la Construcción del Metro de Quito. 11 May 2018. Available online: https://ciudadesiberoamericanas.org/el-bid-aprueba-un-prestamos-de-250-millones-de-dolarespara-la-construccion-del-metro-de-quito/ (accessed on 3 January 2020).

80. Se Requieren USD 16 Millones Más Para Que el Metro de Quito Opere. El Comercio. 2 December 2019. Available online: https://www.elcomercio.com/actualidad/quito-millones-dolares-metro-operacion.html (accessed on 6 January 2020).

81. Armijos, J.P.; Osorio, A.G. Todas las miradas se dirigen al metro de Quito. El País, Madrid, 6 December 2019.

82. Oviedo, L.; Velasco Villacis, A.; Velasco Andrade, D. The Destruction by Metro of Quito of the Patrimony, Tangible and Intangible, of Quito's Historic Center. In World Heritage Watch Report 2018; World Heritage Watch: Berlin, Germany, 2018; pp. 112-118.

83. Corporación Ekos. Estudio de caracterización social, económica y análisis de evaluación de medios de transporte de la población del Distrito Metropolitano de Quito en referencia al proyecto del metro de la ciudad de Quito; Ekos: Quito, Ecuador, 2012. 
84. El Comercio. Lenín Moreno: “Contamos con usted señor Alcalde para que nunca más se ponga en peligro este monumento mundial que es Quito". El Comercio. 6 December 2019. Available online: https: //www.elcomercio.com/actualidad/lenin-moreno-sesion-solemne-quito.html (accessed on 6 January 2020).

85. La Hora. Fomento de la Cultura Metro se quedó en el papel. La Hora. 3 October 2019. Available online: https://lahora.com.ec/quito/noticia/1102276824/fomento-de-la-cultura-metro-se-quedo-en-el-papel (accessed on 27 March 2020).

86. ITDP. The Online BRT Planning Guide. 2016. Available online: https://brtguide.itdp.org/branch/master/guide/ (accessed on 28 February 2020).

87. Perdomo Calvo, J.A. The effects of the bus rapid transit infrastructure on the property values in Colombia. Travel Behav. Soc. 2017, 6, 90-99. [CrossRef]

88. Temenos, C.; McCann, E. Geographies of Policy Mobilities. Geogr. Compass 2013, 7, 344-357. [CrossRef]

89. Dolowitz, D.P.; Marsh, D. Learning from Abroad: The Role of Policy Transfer in Contemporary Policy-Making. Governance 2000, 13, 5-23. [CrossRef]

90. McCann, E.; Ward, K. Policy Assemblages, Mobilities and Mutations: Toward a Multidisciplinary Conversation. Polit. Stud. Rev. 2012, 10, 325-332. [CrossRef]

(C) 2020 by the authors. Licensee MDPI, Basel, Switzerland. This article is an open access article distributed under the terms and conditions of the Creative Commons Attribution (CC BY) license (http://creativecommons.org/licenses/by/4.0/). 